\title{
Gestores municipais do Sistema Único de Saúde: perfil e perspectivas para o Ciclo de Gestão 2017-2020
}

\author{
Municipal managers at the Unified Health System: profile and \\ perspectives for the 2017-2020 Management Cycle
}

\author{
Assis Luiz Mafort Ouverney ${ }^{1}$, André Luís Bonifácio de Carvalho², Nádia Maria da Silva Machado², \\ Marcelo Rasga Moreira1, José Mendes Ribeiro'
}

DOI: 10.1590/0103-11042019S706

1 Fundação Oswaldo Cruz (Fiocruz), Escola Nacional de Saúde Pública Sergio Arouca (Ensp), Departamento de Ciências Sociais (DCS) - Rio de Janeiro (RJ), Brasil. assismafort@gmail.com

2 Universidade Federal da Paraíba (UFPB), Departamento de Promoção da Saúde - João Pessoa (PB), Brasil.

3 Ministério da Saúde (MS), Departamento de Vigilância, Prevenção e Controle das IST, do HIVAids e das Hepatites Virais (DIAHV) - Brasília (DF), Brasil.
RESUMO Este artigo teve como objetivo analisar o perfil e as percepções dos Secretários Municipais de Saúde (SMS) sobre as perspectivas para o Sistema Único de Saúde (SUS) em âmbito nacional, ressaltando as variações apresentadas nas regiões Norte, Nordeste, Centro-Oeste, Sudeste e Sul. Busca-se compreender em que medida a consolidação do SUS tem sido acompanhada da democratização do acesso ao cargo de SMS e da modernização das práticas de gestão pública. Os dados foram coletados com um questionário eletrônico aplicado via web, respondido por 2.313 gestores, no âmbito da Pesquisa Nacional dos Secretários Municipais de Saúde, um estudo nacional, realizado em 26 estados em 2017 e 2018. Os resultados mostram que o cargo de SMS é cada vez mais ocupado por mulheres com pós-graduação, que exercem a função pela primeira vez e com experiência na gestão da atenção primária. Além disso, o estudo ressalta a presença recorrente de limitações estruturais ao aperfeiçoamento da capacidade de gestão local, em especial: a redução do financiamento federal, as dificuldades de acesso a exames e consultas especializadas, a judicialização, o diálogo incipiente com órgãos de controle externo, as insuficiências do papel do gestor estadual no planejamento e na regionalização e a necessidade de formação dos conselheiros municipais de saúde.

PALAVRAS-CHAVE Gestor de saúde. Governo local. Sistema Único de Saúde.

ABSTRACT This article aims to analyze the profile and perceptions of the Municipal Health Secretariats (SMS) about the perspectives for the Unified Health System (SUS) at the national level, highlighting the variations presented in the North, Northeast, Midwest, Southeast, and South regions. It seeks to understand to what extent the consolidation of the SUS has been accompanied by the democratization of access to the SMS position and the modernization of public management practices. The data were collected with an electronic questionnaire applied via web, answered by 2,313 managers, within the scope of the National Survey of Municipal Health Secretaries, a national study carried out in 26 states in 2017 and 2018. The results show that the position of local SUS manager is increasingly occupied by postgraduate women who perform the function for the first time and with previous experience in the management of primary care. In addition, the study highlights the recurrent presence of structural constraints to the improvement of local management capacity, especially the reduction offederal funding, difficulties in accessing specialized exams and consultations, judicialization, incipient dialogue with external control entities, the inadequacies of the state manager's role in planning and regionalization, and the need for training of municipal health counselors.

KEYWORDS Health manager. Local government. Unified Health System. 


\section{Introdução}

A institucionalização do Sistema Único de Saúde (SUS), como política de caráter federativo e intergovernamental, gradualmente, vem estabelecendo as novas competências governamentais, ampliando, especialmente, as atribuições e responsabilidades dos gestores locais.

Tal processo posiciona os(as) Secretários(as) Municipais de Saúde (SMS) no centro de um movimento de transformação setorial caracterizado por constantes inovações conceituais, logísticas, tecnológicas e instrumentais, muitas vezes, em condições heterogêneas, diversas e plurais.

Como consequência, os(as) SMS, cada vez mais, adquirem o status de atores políticos estratégicos na definição e conformação dos rumos da política de saúde, considerando o quantitativo de recursos que gerenciam o tamanho da rede e o volume de profissionais sob sua gestão.

Além disso, a consolidação do papel político exercido por suas entidades de representação corporativa (Conselho Nacional de Secretarias Municipais de Saúde - Conasems e Conselhos de Secretários Municipais de Saúde - Cosems) lhes confere um engajamento privilegiado nos principais fóruns federais e estaduais do SUS, expandindo sua capacidade de articulação política. Assim, suas posições influenciam praticamente todas as estratégias nacionais e regionais de condução da política de saúde. Finalmente, possuem também iniciativas de articulação nos legislativos e nos partidos políticos, além de estabelecerem alianças com diversas instituições do setor saúde, de outras áreas de política pública e com grupos de defesa de direitos humanos e da cidadania'.

O cargo de SMS representa, portanto, um espaço de competição política para as elites locais e torna-se elemento importante do estudo da natureza da configuração do poder local e dos rumos da política de saúde nas esferas estadual e federal. Suas percepções sobre o funcionamento das diversas instâncias do SUS e sobre a implementação, gestão e impactos de políticas e programas consistem em insumos extremamente relevantes para a definição de estratégias de aperfeiçoamento do SUS.

Entretanto, a produção científica setorial não tem conferido a devida atenção ao estudo das características dessas elites gestores locais e de suas percepções sobre o SUS. A maior parte dos estudos publicados nos últimos anos possui abrangência territorial limitada, consistindo em pesquisas realizadas em municípios específicos e microrregiões de saúde. As pesquisas com maior abrangência territorial retratam, no máximo, realidades macrorregionais, sendo raras, as estaduais ${ }^{2-5}$.

Além disso, as dimensões e variáveis de análise empregadas nesses estudos são pouco abrangentes e diferem muito entre si, o que permite apenas conhecer o perfil e as percepções dos gestores de determinadas regiões sobre temas diferentes. Assim, apesar da relevância de tais estudos para seus contextos específicos, as configurações metodológicas neles adotadas não permitem a obtenção de representatividade nacional e dificultam a comparabilidade, impossibilitando uma análise consistente sobre as especificidades regionais do SUS.

Buscando superar essas limitações, este artigo tem como objetivo apresentar e realizar comparações regionais relativas às características do perfil e das percepções dos SMS provenientes dos 26 estados brasileiros. Busca-se analisar em que medida a consolidação do SUS tem sido acompanhada da democratização do acesso ao cargo e da modernização das práticas e estratégias de gestão pública.

Os dados empregados neste artigo são provenientes da Pesquisa Nacional dos Secretários Municipais de Saúde, um estudo abrangente realizado nos anos de 2017 e 2018, os quais foram coletados por meio de um questionário eletrônico aplicado via web. $\mathrm{O}$ estudo foi financiado pelo Ministério da Saúde (MS) por meio do Termo de Execução Descentralizada $\mathrm{n}^{0} 30 / 2015$, destinado ao fomento de estudos voltado para a qualificação da gestão descentralizada do SUS. 


\section{Referencial teórico: descentralização do SUS e capacidade dos governos locais - avanços e limites da democratização e da modernização da gestão pública no setor saúde}

Segundo Carvalho ${ }^{6}$, os governos locais representaram, em boa parte da trajetória histórica brasileira, espaços de exercício do poder das oligarquias regionais formadas por famílias proprietárias de terras e grandes comerciantes, vinculados à economia agroexportadora, sendo os defensores de um padrão tradicional de cultura e organização social.

Para Melo7, o comprometimento do interesse público em favor de manutenção do status e da preponderância das elites patrimonialistas oligárquicas marcou a formação nacional, tendo se perpetuado ao longo da história, apesar do processo de urbanização, industrialização e modernização do País.

Andrade ${ }^{\mathbf{8}}$ afirma que esse padrão somente foi alterado com a Constituição de 1988, que estabeleceu um novo regime de distribuição de competências federativas, de distribuições de recursos tributários e de gestão das políticas sociais, configurando um vigoroso movimento de descentralização para os municípios. Fleury 9 destaca que, ao reduzir e alterar as atribuições do governo central e transferi-las às esferas subnacionais, a descentralização impulsionou um movimento de redefinição da estrutura do Estado centralizador, reforçado ao longo do regime ditatorial, caracterizado pela reduzida amplitude do leque de interesses inseridos na condução das decisões nacionais.

Esse padrão se materializava na centralização dos recursos tributários no nível nacional, tornando os entes subnacionais alinhados automaticamente ao poder central, e na redução dos atores políticos capazes de influenciar na definição das políticas públicas. $\mathrm{O}$ ápice desse processo é encontrado no período autoritário, com a redução dos círculos de poder ao comando militar e a outros atores civis articulados em torno desse núcleo.

Para a autora, a transição democrática, com a Constituição de 1988, introduziu um novo desenho de sistema político que propiciou o empoderamento de novos atores no cenário político nacional, criando meios para aumentar a sua capacidade efetiva de condução dos rumos das políticas públicas, o que tem permitido o reconhecimento da diversidade de demandas sociais anteriormente excluídas e sem capacidade de expressão. A ampliação do escopo de atores e interesses produz efeitos democratizantes em todo o território nacional na medida em que fortalece a esfera local como espaço de decisão e ativa relações que ocorrem na micropolítica de cada município, permitindo a emergência de novas lideranças e articulações em torno de novos projetos locais em cada um dos municípios brasileiros.

Santos e Andrade ${ }^{10}$ destacam que o SUS é o exemplo mais acabado de federalismo cooperativo, em que os interesses são comuns e indissociáveis e devem ser harmonizados em nome dos interesses local, regional, estadual e nacional. Nesse arranjo de relações intergovernamentais, todos são cotitulares dos interesses (da saúde), devendo manter garantida sua autonomia (direção única). Esse conjunto de inovações implementadas nas municipalidades brasileiras conformou uma agenda de reforma do Estado que promoveu expressivas transformações na estrutura e na dinâmica de funcionamento dos governos locais.

Entretanto, esse processo de difusão de inovações foi expressivamente assimétrico tanto em termos temporais quanto territoriais, sendo afetado: 1) pelo contexto político e econômico nacional; 2) pelos dilemas do federalismo brasileiro; e 3) pela estratégia de descentralização empregada em cada etapa da implementação do SUS.

Assim, em virtude das adversidades e incertezas colocadas por um contexto de esgotamento do modelo desenvolvimentista, 
reforma do Estado e priorização da agenda macroeconômica de estabilização monetária, os tempos legal, financeiro e gerencial de implementação das inovações foram muito diferentes. Em virtude disso, foram comuns as crises de subfinanciamento, as limitações para contratação de profissionais, o sucateamento das unidades de prestação de serviços, a baixa capacidade de regulação da oferta privada, as limitações da oferta de exames e serviços especializados, entre outros ${ }^{11-13}$.

No plano federativo, a necessidade de compatibilizar corresponsabilização e autonomia nem sempre resultou em um processo harmônico, podendo ser observados conflitos distributivos por recursos financeiros, posicionamentos contrários das esferas sobre os rumos de políticas, superposição de oferta, estratégias fiscais predatórias, insuficiências de planejamento e coordenação federativa, entre outros dilemas típicos de padrões mais competitivos de federalismo. As disparidades regionais, o esvaziamento do papel dos governos estaduais, as crises setoriais de financiamento, a judicialização, a baixa capacidade de regulação da oferta privada contratada e a insuficiência das estratégias de formação de quadros qualificados têm contribuído para reduzir significativamente a capacidade de governo da gestão pública local no setor saúde ${ }^{\text {14-16. }}$.

Além disso, o início e o desenrolar dos movimentos de transferência de poder, atribuições e recursos não foram automáticos nem regulares, havendo períodos de ruptura e aprofundamento da descentralização, recentralização e, mesmo, estagnação. Cada uma das fases da descentralização teve tempos de formulação e implementação diferentes, e os estados e os municípios foram incorporando-se ao processo por ondas de adesão, reguladas por regras inscritas nas normas operacionais, sendo que, apenas ao final da década de 1990, a descentralização atingiu todo o território nacional, materializada por um padrão de relações intergovernamentais polarizado, com expressiva municipalização e alta regulação normativa e financeira federal ${ }^{17,18}$
Essa percepção é corroborada por Paim e Teixeira ${ }^{19}$, que afirmam que o processo de institucionalização da gestão do SUS pode ser caracterizado como um movimento pendular de descentralização/centralização, regido pelo esforço de se implantar o pacto federativo incorporado à Constituição de $1988^{7}$. Segundo os autores, esse movimento descentralizador foi iniciado com a implementação das Normas Operacionais Básicas de 1993 (NOB 01/93) ${ }^{20}$ e, especialmente, da Norma Operacional Básica de 1996 (NOB 01/96)21, que induziram a redefinição de funções e competências das três esferas de governo (federal, estadual e municipal) no que se refere à gestão, organização e prestação de serviços de saúde, por meio da transferência de recursos (financeiros, basicamente, mas também físicos, humanos e materiais) do nível federal e estadual para os municípios.

O processo de (re)centralização, com ênfase no fortalecimento do papel das Secretarias Estaduais de Saúde, foi desencadeado com a elaboração e implementação da Norma Operacional da Assistência à Saúde (2001/2002) 22 , instrumento de política que pretendia estimular a regionalização da assistência por meio da organização de sistemas microrregionais de saúde, capazes de garantir economia de escala na compra de insumos e a integralidade da atenção, a partir da implementação de redes de serviços que articulassem os vários níveis de atenção.

Os autores ainda destacam que esse processo foi temporariamente interrompido com a mudança de governo em 2003, instalando-se um debate acerca da opção excessivamente 'normativa' adotada durante a década de 1990, o que culminou com a aprovação dos Pactos da Saúde, em $2006^{23}$, novo instrumento de política que pretende instituir um processo de negociação permanente entre gestores, no sentido de garantir a implementação de políticas e ações prioritárias. Com isso, o MS tentou substituir a estratégica adotada anteriormente, qual seja, a de induzir a tomada de decisões no âmbito estadual e municipal a partir de 
incentivos financeiros, por uma outra centrada no compromisso político entre os gestores, a ser construído no espaço das Comissões Intergestores Tripartite, ao nível nacional, e das Comissões Intergestores Bipartite, em cada estado, mediante a assinatura de 'Termos de Compromisso' pactuados politicamente.

Carvalho et al. ${ }^{\mathbf{2 4}}$ afirmam que a recente construção do Pacto pela Saúde e seu aprimoramento com a promulgação do Decreto $\mathrm{n}^{\mathrm{0}} 7.508$, de 28 de junho de $2011^{25}$, que regulamenta aspectos da Lei no ${ }^{\circ} 8.080 / 90$, têm como fundamento principal o respeito aos princípios constitucionais do SUS, com ênfase nas necessidades de saúde da população, o que implica o exercício simultâneo da definição de prioridades articuladas e integradas buscando a melhoria do acesso a ações e serviços de saúde, o fortalecimento do planejamento regional com a consequente definição das redes de atenção nas regiões de saúde, o aprimoramento dos mecanismos de governança e a qualificação dos processos de pactuação tripartite.

Como resultado dessa longa trajetória, os governos locais ampliaram significativamente seu papel em praticamente todos os aspectos relevantes da gestão da política de saúde. As secretarias municipais de saúde passaram a gerenciar a grande maioria das unidades públicas de provisão de serviços de saúde no domínio do SUS, além de assumir também a responsabilidade formal pela contratação, pagamento, monitoramento e avaliação (gestão) de amplo conjunto de unidades privadas. Além disso, aos governos locais também possuem participação política nas instâncias decisórias do SUS em âmbito estadual e nacional, por meio de suas representações corporativas, respectivamente, os Cosems e o Conasems.

Assim, por um lado, o complexo institucional de governança local da saúde, desenvolvido ao longo da descentralização, não só gerencia a maior parte dos recursos do setor como também possui espaço privilegiado no processo de construção da política de saúde em âmbito regional e nacional. Essa expansão expressiva do papel político e das funções exercidas pelas secretarias municipais de saúde exigiu a difusão de um amplo conjunto de inovações de diversas naturezas, ao longo de mais de duas décadas, nos 5.570 municípios brasileiros.

Essas inovações abrangem a emergência de novos atores políticos, a definição de instâncias e espaços institucionais, o estabelecimento de novos canais de intermediação de interesses, a definição de novas regras para a tomada de decisões, a criação de estruturas administrativas, a contratação de quadros, o desenvolvimento de rotinas e políticas de formação, a implantação de unidades diversas de prestação de serviços de saúde, a criação de sistemas de transferência e gerenciamento de recursos financeiros, a definição de rotinas e sistemáticas para aquisição de bens e serviços, entre outras.

Entretanto, por outro lado, os gestores municipais têm que formular e implementar estratégias diferenciadas para conduzir esse complexo local de governança em saúde em um contexto dual de gestão, caracterizado tanto por avanços que abrangem a ampliação de níveis regionais de renda e de oferta de serviços, expansão e diversificação de políticas e programas e ganhos de institucionalidade e de melhoria das instâncias de governança regional, quanto pela persistência de disparidades regionais expressivas, baixa capacidade de coordenação e planejamento, conflitos distributivos, insuficiência de financiamento, judicialização e ausência da participação de atores relevantes do sistema político local e regional na construção das estratégias de regionalização ${ }^{\mathbf{1 4}, 16,26,27}$.

Esse processo é extremamente dinâmico e, a cada ciclo de gestão de quatro anos, correspondente aos mandatos do Poder Executivo local, assumem novos gestores, com perfis que podem variar de forma significativa em relação aos anteriores, e percepções as mais diversas sobre o papel das secretarias municipais de saúde no SUS.

Assim, podemos afirmar que a inevitável mudança de ciclos da gestão do SUS precisa ser estudada e analisada de forma sistemática, 
tendo como um dos meios a caracterização e análise do perfil dos novos gestores municipais e a sua percepção sobre os processos de gestão e participação no âmbito do SUS, propiciando um maior conhecimento dos aspectos inerentes a institucionalização das práticas e processo envolvendo a pactuação e implementação de políticas de saúde.

\section{Metodologia da pesquisa}

\section{Desenho da pesquisa}

Os dados empregados no presente artigo foram coletados no âmbito da Pesquisa Nacional dos Gestores Municipais do SUS, um estudo seccional de abrangência nacional desenvolvido a partir de parceria entre o Departamento de Ciências Sociais da Escola Nacional de Saúde Pública Sergio Arouca/Fundação Oswaldo Cruz (DCS/Ensp/Fiocruz) e o Conasems, com o objetivo de analisar as tendências atuais de caracterização do perfil dos SMS e suas percepções sobre os avanços e desafios do SUS.

A análise do perfil abrangeu as dimensões da origem socioeconômica, características pessoais, situação ocupacional atual, trajetória profissional, trajetória política e vida pública e relação com o cargo de SMS, incluindo as razões de indicação e as motivações para assumir a posição.

O mapeamento das percepções dos gestores sobre o SUS compreendeu o estudo das seguintes dimensões:

1) Relevância dos espaços e instâncias de pactuação intergestores e de controle social (Comissão Intergestores Tripartite - CIT, Comissão Intergestores Bipartite - CIB e Comissão Intergestores Regionais CIR; Conselho Nacional de Saúde - CNS, Conselhos Estaduais de Saúde - CES e Conselhos Municipais de Saúde - CMS);

2) Importância e estágio de implementação dos princípios doutrinários e organizativos do SUS;
3) Situação atual, desafios e perspectivas das políticas estratégicas do SUS, em especial: planejamento, regionalização e redes de atenção, acesso a ações e serviços de saúde, relações federativas, financiamento, judicialização, controle social, gestão do trabalho e educação em saúde;

4) Influência de atores e entidades sobre os processos e práticas de gestão da política local de saúde;

5) Comunicação e transparência - instrumentos e formas utilizadas pelos gestores para disseminar informações e se comunicar com a população;

6) Agendas prioritárias intergestores - principais movimentos dos gestores estaduais, do MS e do Conasems na construção de agendas estratégicas para o ciclo de 2017 a 2020.

A definição das dimensões acima mencionadas, para o estudo do perfil e das percepções dos gestores municipais de saúde, levou em conta o escopo definido em pesquisas anteriores sobre o tema ${ }^{2-5,26,29}$ assim como os subsídios provenientes de entrevistas e reuniões realizadas com membros da direção do Conasems e ex-gestores municipais de saúde.

Essas dimensões foram desdobradas em variáveis específicas, para as quais foram elaboradas questões que compuseram o questionário empregado para coletar os dados da pesquisa, composto por 57 questões fechadas.

Na elaboração das questões, foram empregadas diversas configurações, especificamente ajustadas de acordo como o tipo de informação a ser coletada. As questões sobre o perfil dos gestores seguiram o padrão do Instituto Brasileiro de Geografia e Estatística (IBGE) para a maioria das variáveis, tais como idade, cor/raça, etnia, instrução, remuneração etc., buscando comparabilidade com as pesquisas populacionais do País. As perguntas empregadas para o mapeamento da percepção dos gestores sobre a situação atual, os desafios e as perspectivas de futuro do 
SUS tomaram como base a revisão da literatura setorial, tendo, assim, um número variável de itens em sua composição. Nessas, em geral, solicitava-se ao respondente que identificasse os três principais desafios. Finalmente, nas questões que envolveram a avaliação dos respondentes sobre espaço e instâncias de gestão, empregou-se um padrão de Escala Likert, com cinco opções alternativas, além das opções 'outro' e 'prefiro não responder'.

Concluída a fase de elaboração e validação, as questões foram inseridas e programadas em um formulário eletrônico na plataforma virtual Survey Monkey, o qual foi submetido a diversos testes da equipe de pesquisa até atingir as configurações almejadas. O pré-teste final do questionário foi realizado durante o XXIII Congresso Nacional do Conasems, evento no qual a pesquisa foi oficialmente lançada.

\section{Coleta e sistematização dos dados}

Após o pré-teste, o questionário foi disponibilizado, por meio de um link enviado pela internet, a todos os Cosems, que atuaram disseminando/ repassando aos gestores locais. Cabe destacar que, previamente ao envio do questionário para os gestores, foi encaminhado a cada Cosems um ofício, assinado pelo Presidente do Conasems, explicando a natureza e os objetivos da pesquisa. Para agilizar os trabalhos, foi organizado um grupo técnico de acompanhamento, composto pelos pesquisadores e pelos secretários executivos dos Cosems.

Eles tiveram acesso a um painel de monitoramento on-line contendo informações atualizadas diariamente sobre o preenchimento do questionário pelos SMS de seus respectivos estados. Ao responder o questionário, os participantes se identificavam nominalmente, permitindo manter o controle do conjunto dos respondentes. Mensalmente, a equipe de pesquisa elaborava uma síntese da evolução da coleta de dados, em forma de boletim, e a disponibilizava à direção nacional do Conasems. Com base nessas informações, eram identificados espaços e eventos específicos em cada estado para intensificar os esforços de divulgação e coleta de dados da pesquisa.

Os links de acesso ao questionário ficaram abertos entre julho de 2017 e agosto de 2018, período em que foi registrado um total de 3.899 respondentes, o que representa $70 \%$ dos 5.570 SMS do País. Destes, 2.313 responderam integralmente ao questionário, e 1.532 o fizeram parcialmente. Para as análises do presente artigo, foram considerados somente os dados provenientes dos questionários completos, que representam 41,5\% do universo nacional de secretarias municipais de saúde.

Essa taxa de retorno apresentou algumas variações regionais, com índices maiores nas regiões Centro-Oeste (58\%) e Nordeste (54\%) e menores nas regiões Sudeste e Sul (31\%). A região Norte, por sua vez, manteve-se próxima à média nacional com $44 \%$. Cabe destacar que, excetuando-se os estados Espírito Santo, Minas Gerais, São Paulo, Santa Catarina, Paraná, Rio Grande do Sul, Bahia, Alagoas, Ceará, Goiás e Tocantins, os demais tiveram taxa de retorno superior a $60 \%$, com destaque para Sergipe e Amapá, onde o índice foi de $100 \%$.

Nesses dois últimos casos, os resultados apresentados e discutidos neste artigo são representativos para o conjunto dos municípios de ambos os estados, o que não pode ser afirmado nem para os demais estados, nem para o âmbito nacional, isso porque as taxas de não resposta são expressivas, considerando o objetivo inicial de realização de um censo. Portanto, os resultados são representativos para a população de respondentes, devendo ser relativizadas as afirmações e as comparações realizadas entre as unidades da federação, e destas com o total nacional.

Após encerrado o prazo de coleta na plataforma Survey Monkey, os dados relativos aos questionários completos foram extraídos para um banco de dados no Microsoft Excel ${ }^{\circledR}$ e organizados por respondentes (município), região de saúde, unidade da federação e região do País. Para este artigo, foram selecionados os dados relativos ao perfil dos gestores e a suas percepções sobre o estágio de implementação dos princípios 
doutrinários e organizativos do SUS, a situação atual dos desafios e perspectivas das políticas estratégicas do SUS, a influência de atores e entidades sobre os processos e práticas de gestão da política local de saúde e as agendas prioritárias intergestores - principais movimentos dos gestores estaduais, do MS e do Conasems na construção de agendas estratégicas para 2017 a 2020.

As tabulações mostram os resultados nacionais e as variações regionais para as variáveis selecionadas. Todos os SMS que participaram da pesquisa permitiram o uso dos dados em publicações científicas por meio de Termo de Consentimento Livre e Esclarecido.

\section{Resultados e discussão}

\section{Perfil dos gestores municipais}

Em termos de perfil pessoal, é possível afirmar, com base nos apresentados na tabela 1 , que o gestor municipal do SUS é, em sua maioria, mulher (54\%), branca (59\%), com idade entre 31 e 50 anos (67\%), possui nível superior (81\%) e tem pós-graduação (49\%). Cabe destacar que a única região onde a maioria dos gestores se declara homem é a Norte (55\%). No que tange ao quesito raça/cor, as regiões Norte e Nordeste diferem da situação nacional, apresentando predomínio de gestores pardos e pretos, respectivamente $51 \%$ e $56 \%$. Com relação à escolaridade, a região Norte destaca-se com o menor percentual de graduados (74\%) e pós-graduados (40\%), diferentemente da Sudeste, que possui o maior percentual para ambas, respectivamente $83 \%$ e $50 \%$.

No que tange à trajetória profissional, a enfermagem (26\%) é a profissão predominante entre os gestores do SUS, que, em sua maioria, nunca haviam assumido a função de secretárias de saúde e que tiveram como experiência prévia a coordenação da atenção básica.

Com relação à motivação para assumir as funções de gestor do SUS, destacaram-se fortalecer o SUS (80\%), sendo essa motivação mais prevalente nas regiões Norte, Nordeste e Centro-Oeste; servir à cidade (76\%), com destaque para as regiões Norte e Nordeste, e assumir novos desafios (71\%), com destaque para as regiões Norte, Nordeste e Centro-Oeste.

\begin{tabular}{|c|c|c|c|c|c|c|c|}
\hline \multirow{2}{*}{\multicolumn{2}{|c|}{ Variáveis }} & \multicolumn{5}{|c|}{ Regiões / País } & \multirow{2}{*}{$\begin{array}{r}\text { Brasi } \\
(\mathrm{N}: 2.312)\end{array}$} \\
\hline & & $\begin{array}{r}\text { Norte } \\
(\mathrm{N}: 202) \\
\end{array}$ & $\begin{array}{r}\text { Nordeste } \\
(\mathrm{N}: 961) \\
\end{array}$ & $\begin{array}{r}\text { Centro-Oeste } \\
(\mathrm{N}: 272)\end{array}$ & $\begin{array}{r}\text { Sul } \\
(N: 369) \\
\end{array}$ & $\begin{array}{l}\text { Sudeste } \\
\text { (N:509) }\end{array}$ & \\
\hline \multicolumn{8}{|c|}{ Perfil Pessoal (\%) } \\
\hline \multicolumn{2}{|c|}{ Sexo (feminino) } & 45 & 61 & 58 & 58 & 57 & 58 \\
\hline \multicolumn{2}{|c|}{ Idade (31-50 anos) } & 66 & 66 & 70 & 63 & 69 & 67 \\
\hline \multicolumn{2}{|l|}{ Raça/Cor } & $\begin{array}{r}56 \\
\text { (pardas e pretas) }\end{array}$ & $\begin{array}{r}51 \\
\text { (pardas e pretas) }\end{array}$ & $\begin{array}{r}56 \\
\text { (branca) }\end{array}$ & $\begin{array}{r}90 \\
\text { (branca) }\end{array}$ & $\begin{array}{r}70 \\
\text { (branca) }\end{array}$ & $\begin{array}{r}59 \\
\text { (branca) }\end{array}$ \\
\hline \multirow[t]{2}{*}{ Escolaridade } & Superior & 74 & 82 & 81 & 75 & 83 & 81 \\
\hline & Pós-Grad. & 40 & 50 & 49 & 42 & 50 & 49 \\
\hline \multicolumn{8}{|c|}{ Trajetória Profissional (\%) } \\
\hline \multicolumn{2}{|c|}{ Profissão (enfermeiro) } & 23 & 27 & 27 & 21 & 27 & 26 \\
\hline \multicolumn{2}{|c|}{$\begin{array}{l}\text { Primeira vez que ocupa o cargo } \\
\text { de SMS }\end{array}$} & 61 & 58 & 60 & 52 & 52 & 56 \\
\hline \multicolumn{2}{|c|}{$\begin{array}{l}\text { Cargos Anteriores na Gestão } \\
\text { (Coord. Atenção Básica) }\end{array}$} & 24 & 28 & 20 & 19 & 25 & 25 \\
\hline
\end{tabular}


Tabela 1. (cont.)

\begin{tabular}{|c|c|c|c|c|c|c|}
\hline \multicolumn{7}{|c|}{ Motivação para assumir a função (\%) } \\
\hline Fortalecer o SUS & 83 & 82 & 82 & 74 & 78 & 80 \\
\hline Assumir Desafios & 75 & 72 & 72 & 69 & 71 & 71 \\
\hline Servir a Cidade & 83 & 78 & 77 & 72 & 75 & 76 \\
\hline \multicolumn{7}{|c|}{ Pontos positivos para a Nomeação (\%) } \\
\hline Confiança Pessoal & 67 & 68 & 60 & 56 & 64 & 64 \\
\hline Capacidade de Liderança & 66 & 59 & 60 & 51 & 63 & 59 \\
\hline Competência técnica & 66 & 60 & 61 & 50 & 60 & 59 \\
\hline Capacidade de Dialogar & 34 & 36 & 30 & 32 & 28 & 34 \\
\hline Capacidade de Mobilizar & 31 & 26 & 25 & 25 & 27 & 26 \\
\hline
\end{tabular}

Fonte: Pesquisa Nacional dos Gestores Municipais do SUS.

Ao serem abordados sobre quais seriam os pontos positivos para sua nomeação, os gestores destacaram como primeiro aspecto a confiança pessoal (64\%), com destaque para as regiões Norte e Nordeste; capacidade e liderança e competência técnica (59\%) surgem na sequência, destacam-se, respectivamente, as regiões Norte e Sudeste e Norte e Centro-Oeste.

Por fim, destacaram-se dois atributos provenientes da experiência dos gestores e que dizem respeito à capacidade de dialogar (34\%) e à capacidade de mobilizar (24\%), que tem nas regiões Norte e Nordeste e Norte e Sudeste, respectivamente, as com maior destaque.

O referido perfil revela que o SUS e conduzido: por mulheres, brancas, com mais de 40 anos, com formação superior, pós-graduadas, vinculadas ao curso de enfermagem, oriundas da atenção básica e sem experiência prévia como gestoras municipais.

Essas gestoras afirmam ter aceitado assumir o cargo para fortalecer o SUS, assumir desafios e servir à cidade onde atuam, e que esse convite teve como móvel a confiança do prefeito e quatro atributos específicos: capacidade e liderança, competência técnica, capacidade de dialogar e mobilizar.

\section{Perspectivas para o SUS - Ciclo de Gestão 2017-2020}

\section{PRINCIPAIS DESAFIOS DA GESTÃO DO SUS}

No que tange aos desafios do SUS, a pesquisa explorou seis eixos estratégicos, vinculados à atenção básica, média e alta complexidade, regionalização e gestão, planejamento, controle social, judicialização, gestão do trabalho e financiamento, conforme apresentado na tabela 2.

Com relação à atenção básica, destaca-se como desafio nacional a contrapartida financeira da esfera estadual (50\%), com exceção das regiões Norte e Nordeste, onde foram apontadas, respectivamente, a garantia de insumos e medicamentos (44\%) e a fixação de médicos (48\%) como objetivos prioritários.

Para os desafios vinculados à média e alta complexidade, destaca-se a garantia de consultas, exames e internações em quantidade e qualidade (71\%) como prioridade nacional, com pouca variação entre as regiões.

Com relação à regionalização e à gestão, ressalta-se o fortalecimento das CIR como instâncias de planejamento e pactuação no âmbito regional (56\%) como prioridade nacional, cabendo destacar a ênfase conferida a esse desafio nas regiões Norte (68\%) e Nordeste (61\%). 


\begin{tabular}{|c|c|c|c|c|c|c|c|}
\hline \multirow{2}{*}{\multicolumn{2}{|c|}{$\begin{array}{l}\text { Dimensões da Organização e } \\
\text { Gestão do SUS }\end{array}$}} & \multicolumn{5}{|c|}{ Regiões / País } & \multirow{2}{*}{$\begin{array}{r}\text { Brasil } \\
(\mathrm{N}: 2.312) \\
\end{array}$} \\
\hline & & $\begin{array}{r}\text { Norte } \\
(\mathrm{N}: 202)\end{array}$ & Nordeste & $\begin{array}{r}\text { Sul } \\
(N: 369) \\
\end{array}$ & $\begin{array}{l}\text { Sudeste } \\
(N: 509)\end{array}$ & $\begin{array}{r}\text { Centro-Oeste } \\
(\mathrm{N}: 272)\end{array}$ & \\
\hline \multirow[t]{2}{*}{ Atenção Básica } & desafio & $\begin{array}{l}\text { Garantir insumos e } \\
\text { medicamentos }\end{array}$ & Fixar Médicos & \multicolumn{4}{|c|}{ Garantir contrapartida financeira estadual } \\
\hline & $\%$ & 44 & 48 & 43 & 60 & 58 & 50 \\
\hline \multirow[t]{2}{*}{ Atenção Especializada } & desafio & \multicolumn{6}{|c|}{ Garantia de consultas, exames e internações em quantidade e qualidade } \\
\hline & $\%$ & 57 & 68 & 68 & 60 & 67 & 71 \\
\hline \multirow[t]{2}{*}{ Regionalização } & desafio & \multicolumn{6}{|c|}{ Fortalecimento das CIR como instâncias de planejamento e pactuação regional } \\
\hline & $\%$ & 68 & 61 & 50 & 53 & 51 & 56 \\
\hline \multirow[t]{2}{*}{ Planejamento } & desafio & \multicolumn{6}{|c|}{ Qualificação das equipes gestoras municipais para pratica do planejamento } \\
\hline & $\%$ & 69 & 67 & 67 & 61 & 68 & 66 \\
\hline \multirow[t]{2}{*}{ Controle Social } & desafio & $\begin{array}{l}\text { Apoiar a formação c } \\
\text { de saú }\end{array}$ & s conselheiros & $\begin{array}{l}\text { Divulgar o SUS } \\
\text { para a população }\end{array}$ & Apoiar a formaçã & o dos conselheiros & e saúde \\
\hline & $\%$ & 51 & 48 & 45 & 46 & 43 & 43 \\
\hline \multirow[t]{2}{*}{ Judicialização } & desafio & \multicolumn{6}{|c|}{ Ampliar o conhecimento dos órgãos de controle sobre a gestão do SUS } \\
\hline & $\%$ & 64 & 66 & 56 & 53 & 55 & 57 \\
\hline \multirow[t]{2}{*}{ Gestão do Trabalho } & desafio & \multicolumn{3}{|c|}{$\begin{array}{l}\text { Implementar diretrizes de educação e gestão do trabalho } \\
\text { (fixar trabalhadores nos municípios) }\end{array}$} & $\begin{array}{l}\text { Definir Planos de } \\
\text { Cargos e Salários } \\
\text { na gestão local }\end{array}$ & \multicolumn{2}{|c|}{$\begin{array}{l}\text { Implementar diretrizes de } \\
\text { educação e gestão do trabalho } \\
\text { (fixar trabalhadores nos mu- } \\
\text { nicípios) }\end{array}$} \\
\hline & $\%$ & 51 & 57 & 49 & 51 & 49 & 52 \\
\hline \multirow[t]{2}{*}{ Financiamento } & desafio & \multicolumn{6}{|c|}{$\begin{array}{c}\text { Garantir financiamento estável para o SUS (aperfeiçoar o padrão do gasto e os processos de transferência de } \\
\text { recursos) }\end{array}$} \\
\hline & $\%$ & & & & & & \\
\hline
\end{tabular}

Fonte: Pesquisa Nacional dos Gestores Municipais do SUS.

No que diz respeito aos desafios vinculados ao processo de planejamento, destaca-se a qualificação das equipes gestoras municipais para prática do planejamento em saúde (66\%) como prioridade nacional, com resultados homogêneos em termos regionais.

Com relação ao controle social, destaca-se nacionalmente a necessidade de apoiar o processo de formação dos conselheiros de saúde (43\%), como agenda nacional, a região Sul diferiu das demais regiões, destacando como principal desafio promover ações de informação e conhecimento acerca do SUS na população (45\%).

No que se refere à relação à judicialização, sobressai-se a necessidade de ampliar o conhecimento dos órgãos de controle sobre a dinâmica da gestão no âmbito do SUS (64\%) como prioridade nacional e para todas as regiões.

A implementação e pactuação de diretrizes para políticas de educação e gestão do trabalho (52\%), que favoreçam o provimento e a fixação de trabalhadores de saúde, no âmbito municipal, destacou-se como principal desafio no eixo gestão do trabalho e educação na saúde. Cabe destacar a diferença da região Sudeste, onde a implementação e/ou reformulação de planos de cargos e salários no âmbito da gestão local (51\%) foi a prioridade. No que tange ao financiamento, destaca-se a garantia do financiamento estável e sustentável para o SUS, melhorando o padrão do gasto e qualificando o financiamento tripartite (68\%) em âmbito nacional.

Por fim, a análise conjunta dos principais 
desafios da gestão do SUS assinalados pelos gestores municipais do SUS aponta para a presença de limitações estruturais que compõem uma agenda estratégica nacional de aperfeiçoamento do SUS. Temas como a garantia de consultas e exames especializados, o fortalecimento de instâncias regionais de governança, a qualificação de quadros técnicos para o planejamento, a formação de conselheiros, a aproximação dos órgãos de controle com a dinâmica do SUS e a melhoria do padrão de alocação de recursos são desafios recorrentes apontados pela literatura setorial como barreiras à modernização da gestão local no setor saúde.

\section{IMPLEMENTAC̣ÃO DOS PRINCÍPIOS DO SUS}

Quando indagados sobre o estágio de implementação dos princípios do SUS, conforme apresentado na tabela 3 abaixo, os gestores apontaram que, entre aqueles plenamente implementados, a universalidade (81\%), a hierarquização (74\%) e a equidade (72\%) são os princípios doutrinários com maiores avanços.

Entretanto, dois dos pilares fundamentais do projeto de reforma sanitária do SUS, que são a participação popular (58\%) e a regionalização (66\%), são assinalados como os que ainda demandam políticas especiais para se concretizarem. Essa percepção corrobora a existência de uma agenda de limites estruturais, em âmbito nacional, que aponta para a necessidade de construção de políticas federais e estaduais de apoio aos municípios para ampliar sua capacidade de gestão e governança. Em especial, as dificuldades relativas à regionalização sinalizam, novamente, a relevância da ampliação das estratégias estaduais de planejamento e coordenação regional.

Tabela 3. Distribuição dos Secretários Municipais de Saúde (2017-2020) segundo posição sobre o grau de implementação dos princípios doutrinários e organizativos do SUS (princípios plenamente implantados) (\%)

\begin{tabular}{lrrrrrr}
\hline Princípios do SUS & \multicolumn{7}{c}{ Regiões / País } \\
\cline { 2 - 7 } & $\begin{array}{r}\text { Norte } \\
(\mathbf{N}: \mathbf{2 0 2})\end{array}$ & $\begin{array}{r}\text { Nordeste } \\
\mathbf{( N : 9 6 1 )}\end{array}$ & $\begin{array}{r}\text { Sul } \\
\mathbf{( N : 3 6 9 )}\end{array}$ & $\begin{array}{r}\text { Sudeste } \\
\text { (N:509) }\end{array}$ & $\begin{array}{r}\text { Centro-Oeste } \\
\text { (N:272) }\end{array}$ & $\begin{array}{r}\text { Brasil } \\
\text { (N:2.312) }\end{array}$ \\
\hline Universalidade & 78 & 81 & 87 & 79 & 77 & 81 \\
Hierarquização & 78 & 73 & 78 & 74 & 69 & 74 \\
Equidade & 75 & 72 & 79 & 70 & 67 & 72 \\
Integralidade & 72 & 67 & 73 & 66 & 66 & 68 \\
Descentralização & 70 & 66 & 75 & 70 & 60 & 68 \\
Regionalização & 60 & 63 & 75 & 71 & 57 & 66 \\
Participação Popular & 67 & 57 & 61 & 58 & 51 & 58 \\
\hline
\end{tabular}

Fonte: Pesquisa Nacional dos Gestores Municipais do SUS.

É importante ressaltar as variações regionais de percepção dos gestores sobre a implementação dos princípios do SUS, em especial, os contrastes entre as regiões Sul e Centro-Oeste. Os gestores da região Sul têm uma visão mais positiva no que tange ao processo de implementação dos princípios doutrinários e organizativos, em contraposição aos gestores da região Centro-Oeste.

\section{PROCESSO DECISÓRIO - ATORES E SITUAC̣ÕES ESTRATÉGICAS}

Em relação aos atores que mais influenciam os gestores municipais, ficou clara a forte influência dos prefeitos (59\%), seguida do conselho de saúde (49\%) e do MS (47\%). Quando analisamos a relação dessa influência por região, com relação aos prefeitos, destacam-se, as regiões 
Norte (64\%) e Sul (54\%), como extremos. Com relação aos conselhos de saúde, destacam-se
Nordeste (52\%) e Sudeste (49\%), e com relação ao MS, as regiões Norte (53\%) e Sudeste (44\%).

Tabela 4. Distribuição dos Secretários Municipais de Saúde (2017-2020) segundo percepç̃os sobre atores e agendas estratégicas (\%)

\begin{tabular}{|c|c|c|c|c|c|c|}
\hline & \multicolumn{5}{|c|}{ Regiões / País } & \multirow[b]{2}{*}{$\begin{array}{r}\text { Brasil } \\
(\mathrm{N}: 2.312)\end{array}$} \\
\hline & $\begin{array}{r}\text { Norte } \\
(\mathrm{N}: 202)\end{array}$ & $\begin{array}{r}\text { Nordeste } \\
(\mathrm{N}: 961)\end{array}$ & $\begin{array}{r}\text { Sul } \\
(\mathrm{N}: 369)\end{array}$ & $\begin{array}{l}\text { Sudeste } \\
\text { (N:509) }\end{array}$ & $\begin{array}{r}\text { Centro-Oeste } \\
(\mathrm{N}: 272)\end{array}$ & \\
\hline \multicolumn{7}{|c|}{ Atores Influentes (\%) } \\
\hline Prefeito & 64 & 62 & 54 & 59 & 56 & 59 \\
\hline Conselho de Saúde & 49 & 52 & 50 & 47 & 48 & 49 \\
\hline Mistério da Saúde & 53 & 52 & 44 & 38 & 45 & 47 \\
\hline \multicolumn{7}{|c|}{ Agendas Estratégias (\%) } \\
\hline Agendas do CMS & 50 & 55 & 51 & 56 & 55 & 54 \\
\hline Agendas CIR & 41 & 51 & 44 & 48 & 52 & 49 \\
\hline Relatório de Auditoria & 45 & 48 & 42 & 46 & 46 & 46 \\
\hline
\end{tabular}

Fonte: Pesquisa Nacional dos Gestores Municipais do SUS.

Quanto às situações consideradas estratégicas para a tomada de decisão, destacam-se as agendas do CMS (54\%), agenda com a CIR (49\%) e os relatórios de auditoria (46\%). Quando analisamos essa influência pela expressão nas regiões, verificamos que, para a agenda do CMS, destacam-se o Sudeste (56\%) e o Norte (50\%); para a agenda da CIR, destacam-se as regiões Centro-Oeste (52\%) e Norte (41\%); por fim, com relação aos relatórios de auditoria, destaca-se o Nordeste (48\%) e o Sul (43\%).

Os dados que revelam a predominância dos três atores - prefeito, CMS e MS - podem ser analisados como indicativo da ausência do gestor estadual no cenário da tomada de decisão, e corroboram a permanência de tendências de polarização federativa observadas na dinâmica de relações intergovernamentais do SUS desde a década de 1990. Tal dinâmica se institucionalizou ao longo do processo de implementação do SUS, combinando um expressivo processo de municipalização configurado por estratégias de indução normativa e financeira federal18.

\section{AGENDAS FEDERATIVAS PRIORITÁRIAS PARA O CICLO 2017-2020}

A tabela 5 traz a posição dos gestores sobre as três agendas prioritárias a serem fomentadas no período de 2017 a 2020. Com relação ao MS, os gestores destacaram ampliar o apoio financeiro para programas estratégicos voltados para a melhoria do acesso à população (73\%), ampliar o apoio às ações de atenção básica e vigilância em saúde objetivando fortalecer as ações da porta de entrada do sistema de saúde (32\%) e investir na melhoria dos sistemas de informação para auxiliar os gestores na tomada de decisão (31\%).

A prioridade conferida pelos gestores à ampliação do financiamento federal é unanimidade entre os gestores das cinco regiões do País, o que evidencia tanto a dependência histórica dos municípios das transferências federais para ampliar políticas quanto os impactos da redução proporcional dos aportes do MS nas últimas décadas, quadro esse que se acentuou significativamente com as medidas de austeridade estabelecidas nos últimos anos. 
A qualificação das ações de atenção básica ganhou destaque nas regiões mais desenvolvidas do País (Sul, Sudeste e Centro-Oeste) como segunda agenda a ser priorizada pelo MS. Na região Nordeste, ela é citada como terceira prioridade e não é destacada pelos gestores da região Norte.

É importante destacar ainda que os gestores conferiram destaque a outras prioridades, embora de forma regionalmente fragmentada. É o caso da busca por apoio na construção dos instrumentos de gestão (Plano Municipal, Relatório de Gestão e Programação Anual de Saúde), na região Norte, e a necessidade de definição dos critérios de rateio estabelecidos na Lei $n^{\circ} 141 / 12$, propiciando a divisão equânime dos recursos financeiros do SUS, nas regiões Sul e Sudeste.

Tabela 5. Distribuição dos Secretários Municipais de Saúde (2017-2020) por principais agendas a serem desenvolvias nas três esferas do SUS (20172020) - regiões e Brasil (\%)

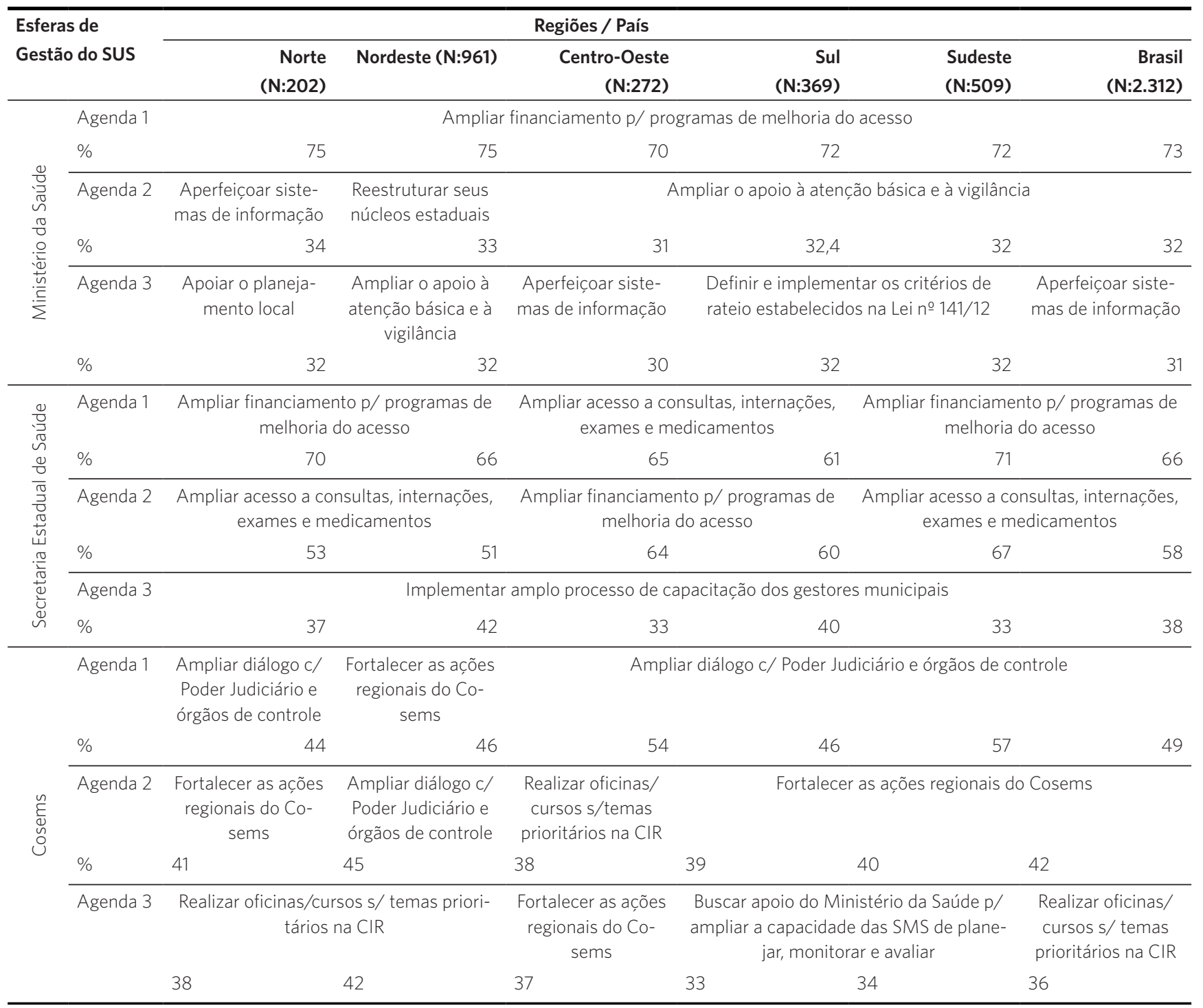

Fonte: Pesquisa Nacional dos Gestores Municipais do SUS. 
Com relação à Secretaria de Estado da Saúde, os gestores destacaram como agendas principais a ampliação do apoio financeiro para programas estratégicos voltados para a melhoria do acesso à população (66\%) e o investimento na melhoria do acesso a consultas, internações, exames e medicamentos em quantidade e qualidade (58\%) e a implementação de amplo processo de capacitação dos gestores municipais (38\%).

Ao analisarmos a composição por regional, observamos que essa sequência de priorização nacional é idêntica nas regiões Norte, Nordeste e Sudeste. As regiões Sul e Centro-Oeste conferiram maior destaque ao investimento na melhoria do acesso a consultas, internações, exames e medicamentos em quantidade e qualidade.

Mais uma vez, o papel da esfera estadual no financiamento e na garantia do acesso à média e à alta complexidade aparece com um dos limites estruturantes na agenda de aperfeiçoamento do SUS, limitando as possibilidades de avanço da regionalização e incentivando a relação direta entre MS e secretarias municipais de saúde no plano federativo.

Finalmente, em relação aos Cosems, os gestores apontaram como prioridades o diálogo com os órgãos de controle e Poder Judiciário, assim como a ampliação do papel da entidade nas regiões de saúde e a qualificação das atividades das CIR. Nas regiões Sul e Sudeste, ainda aparecem, como prioridade para os Cosems, o aprofundamento de seu papel de articulador no MS.

A análise por regiões mostra que há um alinhamento entre as regiões Norte, Nordeste e Centro-Oeste e a situação Brasil, já para as regiões Sul e Sudeste, destaca-se como a terceira ação prioritária fortalecer o diálogo com o MS na perspectiva de ampliar a capacidade dos gestores municipais em torno das práticas de planejamento, monitoramento e avaliação.

\section{Considerações finais}

Os resultados da pesquisa mostram a intensificação de duas tendências principais sobre o perfil dos gestores e a agenda de temas estratégicos para o aperfeiçoamento do SUS, quando são consideradas democratização do acesso ao cargo e à modernização da gestão pública no setor saúde.

Em relação ao cargo de gestor local do SUS, fica claro que esse é cada vez mais ocupado por mulheres com pós-graduação, que exercem a função pela primeira vez e com experiência na gestão da atenção primária. Assim, o conjunto dos resultados analisados aponta como tendência principal a presença de gestoras que possuem a confiança do prefeito, que têm competência técnica e que apresentam capacidade de liderar, mobilizar e dialogar, requisitos primordiais para as práticas e processos de gestão local. Por outro lado, a abertura do cargo para gestores negros ainda é insuficiente, o que reforça a necessidade de ampliar as políticas de cotas para acesso dessa parcela da população ao ensino superior nas áreas da saúde, com já apontado em estudos anteriores sobre o temal.

Com relação aos desafios da gestão, ficou evidente a preocupação das gestores com temas inerente a quatro núcleos centrais: 1) a garantia de financiamento estável e sustentável para o SUS, objetivando melhorar o padrão do gasto tripartite; 2) a melhoria do acesso à consulta e a exames; 3) o fortalecimento da CIR como espaço de qualificação da regionalização, trazendo assim uma maior institucionalidade na sua atuação por meio da capacitação das equipes gestões e da garantia do provimento dos trabalhadores; e 4) um terceiro componente voltado para a qualificação dos conselheiros de saúde e para a ampliação do diálogo com os órgãos de controle.

Esses desafios foram pautados no âmbito de um sistema que, ao completar 30 anos, tem, em seus princípios doutrinários, destaque para a universalidade como o de mais forte expressão e a integralidade como o de mais frágil no que tange à implementação. Diferentemente, os princípios organizativos 
apresentaram-se na visão das gestoras como mais dificuldade na implementação, ficando explicitada uma visão mais otimista com relação à hierarquização e uma mais crítica com relação à participação popular.

As gestoras, como atores políticos, movem-se tendo como base forças e agendas; ademais, ficou explícita a força dos prefeitos, do conselho de saúde e do Ministério em sua tomada de decisão, sendo preocupante a ausência do Estado nesse contexto, fato que necessita de um aprofundamento, tendo em vista a expressão dos desafios e a proposta das agendas de intervenção apresentadas.

Por fim, as prioridades nas agendas vão ao encontro dos desafios do SUS ao versarem sobre aspectos do financiamento tripartite, sobre a melhoria de acesso a consultas e exames, sobre aprimorar a relação operacional entre vigilância e atenção básica, sobre aprimorar os sistemas de informação para a tomada de decisão, sobre qualificar os gestores e sobre fortalecer os espaços de gestão regional.

\section{Colaboradores}

Ouverney ALM (0000-0002-8581-3777)*: concepção, planejamento, análise e a interpretação dos dados. Carvalho ALB (0000-00030328-6588)*: concepção e delineamento do estudo, análise e interpretação dos resultados e redação do artigo. Machado NMS (00000001-9334-9305)*: concepção, planejamento, modelagem de instrumento de coleta, coleta de dados, monitoramento do sistema de coleta de dados, sistematização e análise dos dados, e contribuição de conteúdo. Moreira MR (00000003-3356-7153)*: revisão crítica do conteúdo. Ribeiro JM (0000-0003-0182-395X)*: elaboração do estudo, metodologia e revisão crítica de conteúdo. 


\section{Referências}

1. Fleury S. Democracia e Inovação na Gestão Local da Saúde. Rio de Janeiro: Cebes/Fiocruz; 2014.

2. Vermelho SC, Figueiredo G. A percepção dos secretários municipais de saúde sobre a gestão do trabalho e da educação na rede pública do Sistema Único de Saúde (SUS). Saúde Soc. 2017; 26(2):382-396.

3. Andrade NA, Lanza LMB. A percepção de gestores municipais de saúde em relação ao enfrentamento à mortalidade infantil em territórios da $22^{\mathrm{a}}$ regional de saúde do Paraná: elementos que antecedem a PEC dos 20 anos. Humanidades \& Inovação. 2018; 5(11):127-140.

4. Martins MD, Costa CF. Gestão por competências: O perfil dos secretários municipais de saúde do estado do Rio Grande do Sul. In: Encontro de Gestão de Pessoas e Relações de Trabalho 4º; 2013 nov 3-5; Brasília, DF: Associação Nacional de Pós-Graduação e Pesquisa em Administração - Anpad. [acesso em 2019 fev 14]. Disponível em: http://www.anpad.org. br/admin/pdf/EnGPR130.pdf.

5. Arruda CAM, Pessoa VM, Barreto ICHC, et al. Perceptions of city health managers about the provision and activity of physicians from the More Doctors Program. Interface (Botucatu). 2017; 21(supl1):1269-80.

6. Carvalho JM. Cidadania no Brasil. Rio de Janeiro: Civilização Brasileira; 2003.

7. Mello MABC. Municipalismo, nation-building e a modernização do Estado no Brasil. Rev. Bras. Ci. Soc. 1993; 23:08-100

8. Andrade AGA. O município na política brasileira. In: Avelar L, Cintra AO, organizadores. Sistema político brasileiro: uma introdução. Rio de Janeiro/São Paulo: Konrad-Adnauer-Stiftung, UNESP; 2007. p. 205-221.

9. Fleury S. Políticas Sociais e democratização do poder local. In: Vergara SC, Correa VLA, organizadores. Proposta para uma Gestão Pública Municipal Efetiva. Rio de Janeiro: FGV; 2003. p. 91-115.
10. Santos L, Andrade MOL. SUS: O espaço da Gestão Inovadora e dos Consensos Interfederativos. Aspectos jurídicos, administrativos e financeiros. Campinas: Conasems-Idisa; 2007.

11. Noronha JC, Tavares L. A política de saúde no Brasil nos anos 90. Ciênc. Saúde Colet. 2001; 6(2):445-450.

12. Faleiros VD, Senna JD, Vasconcellos LF, et al. A Construção do SUS: Histórias da Reforma Sanitária e do Processo Participativo. Brasília, DF: Ministério da Saúde; 2006.

13. Abrúcio FL. A coordenação federativa no Brasil: a experiência do período FHC e os desafios do governo Lula. Rev. Sociol. Polit. 2005; 24:41-67.

14. Ribeiro JM, Moreira MR, Ouverney AM, et al. Federalismo e políticas de saúde no Brasil: características institucionais e desigualdades regionais. Ciênc. Saúde Colet. 2018; 23(6):1777-1789.

15. Arretche M. Financiamento federal e gestão local de políticas sociais: o difícil equilíbrio entre regulação, responsabilidade e autonomia. Ciênc. Saúde Colet. 2003; 8(2):331-345.

16. Lima LD, Viana ALA, Machado CV, et al. Regionalização e acesso à saúde nos estados brasileiros: condicionantes históricos e político-institucionais. Ciênc. Saúde Colet. 2012; 17(11):2881-2892.

17. Levcovitz E, Lima LD, Machado CV. A Política de Saúde nos Anos 1990: relações intergovernamentais e o papel das normas operacionais básicas. Ciênc. Saúde colet. 2001; 6(2):269-291.

18. Ouverney AM, Fleury S. Polarização federativa do SUS nos anos 1990: uma interpretação histórico-institucionalista. Rev. Adm. Pública. 2017; 51(6):1085-1103.

19. Paim JS, Teixeira CF. Política, planejamento e gestão em saúde: balanço do estado da arte. Rev. Saúde Pública. 2006; 40(esp):73-8. 
20. Brasil. Ministério da Saúde. Portaria $\mathrm{n}^{0} 545$, de 20 de maio de 1993. Estabelece normas e procedimentos reguladores do processo de descentralização da gestão das ações e serviços de saúde, através da Norma Operacional Básica, SUS 01/93. Diário Oficial da União. 24 maio 1993.

21. Brasil. Ministério da Saúde. Portaria $n^{\circ} 2.203$, de 5 de novembro de 1996. Redefine o modelo de gestão do Sistema Único de Saúde, constituindo, por conseguinte, instrumento imprescindível à viabilização da atenção integral à saúde da população e ao disciplinamento das relações entre as três esferas de gestão do Sistema, através da Norma Operacional Básica, SUS 01/96. Diário Oficial da União. 6 Nov 1993.

22. Brasil. Ministério da Saúde. Portaria no 95, de 26 de janeiro de 2001. Aprova a Norma Operacional da Assistência à Saúde - NOAS-SUS 01/2001 que amplia as responsabilidades dos municípios na Atenção Básica; define o processo de regionalização da assistência; cria mecanismos para o fortalecimento da capacidade de gestão do Sistema Único de Saúde e procede à atualização dos critérios de habilitação de estados e municípios. Diário Oficial da União. 27 Jan 2001.

23. Brasil. Ministério da Saúde. Portaria no 399, de 22 de fevereiro de 2006. Divulga o Pacto pela Saúde 2006 - Consolidação do SUS e aprova as Diretrizes Operacionais do Referido Pacto. Diário Oficial da União. 23 Fev 2006.

24. Carvalho ALB, Guerreiro JV, Rodrigues RM, et al. O pacto dos indicadores da Atenção Básica: um instrumento de monitoramento e avaliação da ges- tão do SUS na Paraíba. Divulg. saúde debate. 2000; (20):46-51.

25. Brasil. Decreto $n^{0} 7.508$, de 28 de junho de 2011. Regulamenta a Lei n 8.080 , de 19 de setembro de 1990, para dispor sobre a organização do Sistema Único de Saúde - SUS, o planejamento da saúde, a assistência à saúde e a articulação interfederativa, e dá outras providências. Diário Oficial da União. 29 Jun 2011.

26. Moreira MR, Ribeiro JM, Ouverney AM. Obstáculos políticos à regionalização do SUS: percepções dos secretários municipais de Saúde com assento nas Comissões Intergestores Bipartites. Ciênc. Saúde Colet. 2017; 22(4):097-1108.

27. Machado CV, Lima LD, Viana ALA, et al. Federalismo e política de saúde: comissões intergovernamentais no Brasil. Rev. Saúde Publ. 2014; 48(4):642-650.

28. Santos AR. Metodologia científica: a construção do conhecimento. 7. rev. ed. Rio de Janeiro: Lamparina; 2007.

29. Fleury S, Mafort A, Molle RC. Democratização do poder local e as dimensões da inovação em saúde: desafios metodológicos da investigação. In: Fleury S. Democracia e inovação na gestão local da saúde. Rio de Janeiro: Cebes/Fiocruz; 2014. p. 121-199.

Recebido em 22/03/2019 Aprovado em 07/08/2019

Conflito de interesses: inexistente

Suporte financeiro: Ministério da Saúde por meio do Termo de Execucão Descentralizada no 30/2015 